
Paper 2008-03

Center for Research in Economic Analysis University of Luxembourg

\title{
The Dark Side of Global Integration: Increasing Tail Dependence
}

available online : $h$ ttp://fdef.uni.lu/index.php/fdef_FR/economie/crea/discussion_papers/2008

Michel Beine, University of Luxembourg

Antonio Cosma, University of Luxembourg Robert Vermeulen, University of Luxembourg

September 24, 2008 


\title{
The Dark Side of Global Integration: Increasing Tail Dependence*
}

\author{
Michel Beine ${ }^{\dagger}$ \\ Antonio Cosma \\ Robert Vermeulen ${ }^{\S}$
}

September 8, 2008

\begin{abstract}
We measure stock market co-exeedances using the methodology of Cappiello, Gerard and Manganelli (2005, ECB Working Paper 501). This method is based on quantile regressions and enables us to measure comovement at each point of the return distribution. First, we construct an annual co-exeedance probability for the $5,10,25,75,90$ and 95 percent return quantiles using daily data from 1974-2006. Next, we explain these probabilities in a panel gravity model framework. This analysis shows that macroeconomic events asymmetrically influence comovement of upper and lower tail returns. Financial liberalization has a positive impact on comovement across the return distribution, but its effect is strongest on the left tail quantiles. Trade competition weakly impact the $5 \%, 10 \%$ and $95 \%$ quantiles, but has a stronger influence on the other quantiles. Industrial dissimilarity has a strong effect on both tails, but not on the $25 \%$ and $75 \%$ quantiles. Exchange rate volatilities have a strong effect only on the $5 \%$ and $10 \%$ quantiles. However, the introduction of the euro has its most pronounced effect on upper quantile comovement.
\end{abstract}

Keywords: stock market comovement, trade integration, financial integration

JEL Codes: F15, F36, F41, G15

\footnotetext{
${ }^{*}$ We thank participants at the $2^{\text {nd }}$ Methods in International Finance Workshop in Barcelona for useful comments. All errors remain ours.

${ }^{\dagger}$ CREA, University of Luxembourg, 162A Avenue de la Faiencerie, L-1511 Luxembourg, Luxembourg

${ }^{\ddagger}$ CREFI, Luxembourg School of Finance, University of Luxembourg, 4 rue Albert Borschette, L-1246 Luxembourg, Luxembourg

${ }^{\S}$ Corresponding author. CREA, University of Luxembourg, 162A Avenue de la Faiencerie, L-1511 Luxembourg, Luxembourg and Department of Economics, Maastricht University, PoBOX 616, 6200 MD Maastricht, The Netherlands (e-mail: robert.vermeulen@uni.lu, tel. +352-4666446675, fax. +352-4666446341)
} 


\section{Introduction}

Over the last thirty years, emerging and developed countries have been undergoing a large globalization process. Most countries have become increasingly integrated, both in terms of real and financial transactions. The academic literature tends to emphasize the crucial role of trade and financial openness for the economic development of countries. Trade integration has been identified as a major source of growth by the growth literature (Wacziarg and Welch, 2008). Likewise, the process of financial liberalization has been found to foster the economic development of a large set of countries including the less developed ones (see for instance Bekaert et al., 2005).

Globalization reflected by trade and financial integration is likely to have a bright and a dark side for investors. The bright side of globalization is the opportunity to diversify their assets worldwide. The openness of the global financial system allows investors to easily buy and sell financial assets in a large number of financial markets. In turn, this might allow them to grab interesting opportunities and hence boost their long run investment returns. Nevertheless, in terms of risk management, the impact of integration is not so obvious. Indeed, impact in terms of diversification will be beneficial to the extent that globalization does not lead to an increase in the degree of comovement between international stock markets. This is especially true if liberalization tends to increase stock market comovement during periods of financial downturn, exactly when the positive effects of diversification are most needed.

The main objective of this paper is to test whether globalization exhibits a dark side for international investors in quest for portfolio diversification. To this aim, we look at whether trade and financial integration tends to increase the degree of comovement on the left hand side of the return distribution. So far, while there has been an extensive empirical literature devoted to the impact of integration in terms of stock market correlations, no study has been able to identify the impact on the different regions of the support of the distribution of stock returns ${ }^{1}$. We rely on a recently developed codependence methodology by Cappiello et al. (2005) in order to determine how

\footnotetext{
${ }^{1}$ See next section for a review of the literature. Existing studies include among many others Bekaert and Harvey (1995); Forbes and Rigobon (2002); Chinn and Forbes (2004); Dellas and Hess (2005); Beine and Candelon (2007).
} 
two assets comove in a certain part of the return distribution. We combine this quantile regression approach along with a subsequent dynamic panel data analysis to address a couple of specific questions that have not been considered in the literature. In particular, we address two specific questions that turn out to be crucial for the international investor. First, do various forms of macroeconomic integration affect stock market comovement in all parts of the return distribution? In other words, we investigate whether integration exerts some asymmetric effects on the degree of stock market comovement. Second, we try to determine which forms of integration do affect the probability of having simultaneous extreme negative returns across international stock markets. Addressing this question allows us to measure the likelihood of future global stock market contagion.

Using stock market index data of seventeen mostly developed countries we study 136 bilateral relationships during 1974-2006. For each pair we estimate an annual probability that two markets jointly experience tail comovement. These annual bilateral probabilities are analyzed in a dynamic panel framework following Beine and Candelon (2007), which takes explicitly care of econometric problems such as unobserved heterogeneity and cross-sectional dependence. Within this framework, we relate tail comovement to several explanatory variables used to proxy for global integration: trade, financial liberalization, industrial dissimilarity and exchange rate volatility.

Results show that trade integration increases comovement mostly at the center of the return distribution, but less in the tails. It seems that countries, that compete more in the same export markets experience larger return comovements. Financial liberalization increases comovement across the entire return distribution, but the effect is stronger for the left tail. Hence, open financial markets increase the likeliness of a joint crash in all markets.

When countries have a more similar industrial structure both lower and upper tail comovement increases, whereas this effect is not present for more central quantiles. It appears that the magnitude of this effect is similar in both tails. Also a lower exchange rate volatility increases most the probability of two countries experiencing very bad returns at the same time. However, the elimination of all exchange rate movements between several European countries due to the introduction of the euro is seen to have the largest impact on the comovements in the top part of the distribution.

The paper is organized as follows. Section 2 provides a literature re- 
view on methodologies to measure comovement and which macroeconomic variables seem to impact comovement. Section 3 explain the methodology to measure comovement and introduces the gravity model. The explanatory variables are introduced in section 4 . Results are discussed in section 5 together with robustness checks. Section 6 concludes.

\section{Literature Review}

This paper builds on a vast literature aiming to measure and explain stock market comovements. ${ }^{2}$ A common feature of this literature is that it measures the average effect of factors in terms of comovement, neglecting the diverse impact that these factors can have on different regions of the joint return distribution. This paper addresses the last issue.

There are roughly three approaches to measure international stock market comovements. The first approach uses first and second moments of the return series, whereas the second uses factor structures and the third is based on extreme value theory.

Not surprisingly, within the first approach, correlation of returns across markets is by far the most widely considered moment to assess the joint behavior of two stock market return series.

One first evidence stemming from this research stream shows that correlations between international stock markets vary over time, indicating that benefits from international diversification are time-varying (Longin and Solnik, 1995). These authors show that correlation has been increasing since the 1960s leading to smaller diversification benefits. Because international investment opportunities have been increasing during these same decades, leading to more diversification possibilities, it is unclear what the net effect of globalization on risk diversification is. Goetzmann et al. (2005) study long term stock market correlations using 150 years of data and find a Ushaped pattern in average correlation. There appears to be a strong peak in average correlations during the Great Depression. This peak is potentially caused by high volatility and not simply increased dependence per se. As it has been shown theoretically by Forbes and Rigobon (2002), correlation is biased upwards in periods of high volatility. Hence, correlations give a

\footnotetext{
${ }^{2}$ For extensive reviews consult the survey articles of Karolyi and Stulz (2003) and Dungey et al. (2005).
} 
misleading picture of actual market dependencies. For instance, during the period of the Asian crisis, characterized by turbulent stock market movements, it appears that correlations, once corrected for the high volatility bias, did not increase.

Focusing on the determinants of correlations in general and on the impact of integration in particular, Bekaert and Harvey (2000) show for a sample of emerging countries that financial liberalization decreases the cost of capital and increases correlations with other markets. This finding suggests that correlations increase due to globalization.

Besides its time dimension, the study of globalization has also an important spatial component. Using correlation as the dependent variable in a gravity model, Flavin et al. (2002) show that geographical (i.e. time constant) variables also matter for stock market comovement. ${ }^{3}$ Correlations are negatively related to physical distance between stock markets, but positively related to market size. Although financial assets are easier to transfer than physical goods, the importance of geography also holds for these markets. ${ }^{4}$

The strong impact of trade and financial integration on stock market comovement also applies to European countries, see Wälti (2006). This last author stresses the role of exchange rate volatility and the introduction of the euro to explain the large increases in correlation among European stock markets. Beine and Candelon (2007) use the same gravity model approach to study only developing countries. They too document a large positive impact of bilateral trade and trade/financial liberalization on stock market comovement. However, Beine and Candelon (2007) deal explicitly with the problems of unobserved heterogeneity and consider a dynamic model. The dynamic model is able to deal with the persistence of correlation in the residuals.

A second strand of the literature relies on a factor model approach, which is in turn based on the International CAPM. For each type of risk factor a factor loading is calculated, indicating the importance of the relative risk factor. Bekaert et al. (2008) test several factor models such as CAPM, APT and the Heston and Rouwenhorst (1994) model to study international stock

\footnotetext{
${ }^{3}$ The gravity model is a popular tool in the trade literature to analyze bilateral trade relationships. For a recent application to trade costs consult the survey of Anderson and Van Wincoop (2004).

${ }^{4}$ This observation is related to the so called home bias (Lewis, 1999), with overinvestment in the domestic financial market.
} 
market comovements. The APT model which uses global and local factors best explains the covariance structure. These factors are determined by taking the first three principal components and allowing these to vary over time. This finding confirms the presence of common factors, but it is not clear what each common factor exactly captures.

Chinn and Forbes (2004) estimate a factor model incorporating global, industry, cross country and country specific factors. The resulting factor loadings are used to study the impact of trade and financial variables on stock market comovement. It appears that bilateral trade is the most important factor determining stock market comovement.

A third approach considers extreme dependence measures to assess the probability of a joint crash in two or more markets. Starting from extreme value theory Hartmann et al. (2004) develop an extreme dependence measure, which aims to capture the probability that two markets co-crash. The authors find that joint stock market crashes are much more likely to occur than what a multivariate normal distribution would suggest. Interestingly, they also document a flight to quality from stocks to bonds if the former market crashes. This results in a boom in the bond market.

In the context of contagion Bae et al. (2003) conclude that information on the joint occurrence of extreme returns is more useful than the one obtained by assuming a normal, student-t or GARCH model for the multivariate distribution. They conclude that interest rates, exchange rates and stock market volatility provide predictable power on the likeliness of contagion. Evidence on different codependencies of extremely low vs. extremely high returns is mixed. However, in the extreme value framework it is necessary to select an arbitrary cutoff point (e.g. $8 \%$ loss) beyond which a return is considered extreme, and results may be threshold dependent.

Extreme codependence measures are popular in the Value at Risk (VaR) literature, where $\mathrm{VaR}$ is the standard method to assess market risk for a single return series. The basic idea of $\mathrm{VaR}$ is to determine a potential maximum loss with a small (e.g. 5\%) probability of losing more. Then the $\mathrm{VaR}$ is a quantile of a loss distribution. It tells us the value such that there is, for instance, a $5 \%$ probability of losing more than that amount. In order to assess risk at any point in the return distribution Engle and Manganelli (2004) introduce the CAViaR method. The CAViaR method directly models the return quantile generating process. 
In line with the literature, we mainly focus on the impact of trade and financial integration on comovements. Nevertheless, we include as additional determinants of comovement other control variables that have received attention in earlier works. An example is exchange rate volatility. Using a multivariate GARCH framework, Fratzscher (2002) shows that exchange rate volatility negatively impacts stock market comovements. The elimination of exchange rate volatility due to the introduction of the euro in 1999 led to an increased comovement for EMU countries. In addition, a couple of authors (e.g. Roll, 1992), document the role of industry structure on stock market comovement. Stock markets with a similar industry structure tend to comove more than stock markets with a very different industry composition. Hence, to the extent that industry structures become dissimilar over the investigated period, it is important to account for such a development in the specification of a model to be estimated. Given our panel data approach and the inclusion of cross-section fixed effects, we are able to account for the influence of time-constant factors such as geographical distance between markets (Flavin et al., 2002) or language similarity (ref). Likewise, the time series dimension allows us to include period fixed effects that capture the role of common factors on the comovement. This can be seen as an alternative to the inclusion of global observable variables such as US interest rates (Chinn and Forbes, 2004).

\section{Measuring and explaining comovement}

\subsection{Measuring Comovement}

Bilateral stock market comovements are measured using the methodology of Cappiello et al. (2005), which in turn is based on the CAViaR method developed in Engle and Manganelli (2004). ${ }^{5}$ Given a time series $\left\{y_{t}\right\}_{t=1, \ldots, T}$, for instance the returns of a stock market, the CAViaR method aims to model only one specific quantile $q_{\theta t}$ of the conditional distribution of returns, that is the value for which $\operatorname{Pr}\left[\mathrm{y}_{t}<\mathrm{q}_{\theta t} \mid \Omega_{t}\right]=\theta$ holds, where $\mathrm{y}_{t}$ is the actual return, $\Omega_{t}$ the information set up to time $t$ and $\theta$ is the probability level (e.g. 10\%) corresponding to the quantile whose process is to be modeled. In words, $\mathrm{q}_{\theta t}$ is the value such that there is a $\theta \%$ probability that $\mathrm{y}_{t}$ is lower

\footnotetext{
${ }^{5}$ CAViaR: Conditional Autoregressive Value at Risk by Regression Quantiles.
} 
than it and a $(1-\theta \%)$ probability that $\mathrm{y}_{t}$ is higher.

An explicit data generating process describing the behavior of the quantiles is necessary to calculate the regression quantiles $\mathrm{q}_{\theta t}$. Following Cappiello et al. (2005) the CAViaR specification is: ${ }^{6}$

$$
q\left(\beta_{\theta}\right)_{t}=\beta_{1}+\beta_{2} * y_{t-1}+\beta_{3} * q\left(\beta_{\theta}\right)_{t-1}+\beta_{4} * y_{t-2}+\beta_{5} *\left|y_{t-1}\right| .
$$

The parameter vector $\beta_{\theta}$ is estimated by minimizing the objective function:

$$
\min _{\beta_{\theta}} T^{-1} \sum_{t=1}^{T} \rho_{\theta}\left(y_{t}-q_{t}\left(\beta_{\theta}\right)\right),
$$

where $\rho_{\theta}(\lambda)=[\theta-I(\lambda \leq 0)] \lambda$ is the quantile loss function, $I(\cdot)$ the indicator function, and $\theta$ the probability level. This method, first introduced by Koenker and Bassett Jr. (1978), ensures that asymptotically there are $\theta \cdot T$ exceedances, that is realizations $\mathrm{y}_{t}$ such that $\mathrm{y}_{t}<\mathrm{q}_{\theta t}$. However, it may happen in finite samples that the number of exceedances does not equal the theoretical value $\theta \cdot T$. In order to correct for this finite sample effect, a set of yearly dummies $\delta=\left\{d_{t}\right\}_{t=1, \ldots, T}$ is included in (1), giving the new specification for the quantile process:

$q\left(\beta_{\theta}, \delta\right)_{t}=\beta_{1}+\beta_{2} * y_{t-1}+\beta_{3} * q\left(\beta_{\text {theta }}, \delta\right)_{t-1}+\beta_{4} * y_{t-2}+\beta_{5} *\left|y_{t-1}\right|+\delta_{1} d_{1}+\ldots+\delta_{T} d_{T}$.

Due to the long time series available, in practical implementations it is often numerically infeasible to minimize (2) relative to the set of parameters $\left\{\beta_{\theta}, \delta\right\}^{7}$. We then perform a two step estimation procedure. In a first step we solve the minimization problem (2) with respect to $\beta_{\theta}$ using the specification (1) for the conditional quantile. We then plug the estimates $\hat{\beta}_{\theta}, \mathrm{i}=1, \ldots, 5$ into (3) to obtain a vector $\tilde{q}_{\theta}=\left\{q(\hat{\beta}, \delta)_{t}\right\}_{t=1, \ldots, T}$. Finally, we substitute the $\tilde{q}_{t}$ into (2) to obtain a new expected quantile loss function that we minimize to obtain the estimates of $\delta_{t}$. The set of estimates we obtain from the above procedure delivers a fitted process $\hat{q}_{t}$ such that the yearly rate of exceedances matches the nominal value of $\theta$.

The following step is to build an indicator vector of exceedances, $\mathrm{I}_{t}^{Y}\left(\hat{\beta}_{\theta}\right) \equiv$ $I\left(y_{t}<q_{\theta t}\right)$, that takes the value one for each date in which an exceedance

\footnotetext{
${ }^{6}$ In Cappiello et al. (2005) $\beta_{4}$ is constrained as $-\beta_{2} * \beta_{3}$.

${ }^{7}$ In our implementation it implies estimating 37 parameters jointly.
} 
takes place, i.e. $\mathrm{y}_{t}<\mathrm{q}_{\theta t}$, and value zero otherwise. This procedure is repeated for each time series that enters the dataset. More specifically, each time series is given by returns on stock indexes in different countries. Since our analysis focuses on comovements between series, we need to build a measure of "co-exeedance", that is a measure of the frequency at which the index returns in two different countries, $\mathrm{x}_{t}$ and $\mathrm{y}_{t}$, lie at the same date below the value of the respective quantiles, $\mathrm{q}_{\theta t}^{Y}$ and $\mathrm{q}_{\theta t}^{Y}$. This is obtained by multiplying the two indicator vectors to obtain the new variable $I_{t}^{X Y}\left(\hat{\beta}_{\theta}\right) \equiv I_{t}^{X}\left(\beta_{\text {theta }}\right) \cdot I_{t}^{X}\left(\beta_{\text {theta }}\right)$. Finally, we pass from conditional "coexeedance" frequencies to "co-exeedance" probabilities, that is the probability of $y_{t}<q_{\theta t}^{Y}$ conditional on $x_{t}<q_{\theta t}^{X}$ at date $t .^{8}$ In order to do so, it suffices to run a regression of $\mathrm{I}_{t}^{X Y} / \theta$ on a constant and dummy yearly variables. The coefficients of the dummy variables are estimates of the time varying conditional co-exeedance probabilities $p_{x y, t}(\theta)$. For more details and proof of the consistency of the estimators, see Cappiello et al. (2005). The analysis is conducted in Matlab and based on the codes of Simone Manganelli.

When compared with other methods to analyze stock return comovements, the methodology of Cappiello et al. (2005) offers certain advantages. First, quantile regression is effective as a tool for exploring and modeling the nature of dependence of the return distribution on the conditioning variables, when the latter have different effects on different parts of the conditional distribution of the returns. This is particularly important if there are asymmetries in the impact of integration on the comovement of financial indexes. Alternatives based on modeling first and/or second moments of return series, such as correlation (Forbes and Rigobon, 2002, e.g.) do not allow for this possibility. They focus on one single point of the conditional distribution function, while in the framework of quantile regression, any value of $\theta$ (e.g. $1 \%$ or $90 \%$ ) can be chosen, allowing to measure codependence on any subset of the support of the joint distribution ${ }^{9}$. Moreover, due to its flexibility, the CAViaR method is not constrained in the choice of the quantile to model, whereas in measures based on extreme value theory the choice is constrained by the threshold level beyond which asymptotic theory applies (e.g. Danielsson and De Vries, 2000).

\footnotetext{
${ }^{8}$ Note that $P\left(y_{t}<q_{\theta t}^{Y} \mid x_{t}<q_{\theta t}^{X}\right)=P\left(x_{t}<q_{\theta t}^{X} \mid y_{t}<q_{\theta t}^{Y}\right)$.

${ }^{9}$ In a finite sample only few observations are available for the extreme quantiles resulting in inaccurate estimates.
} 
Engle and Manganelli (2004) construct the in-sample DQ test to formally test if the selected CAViaR model in Equation (3) is a correct specification of the return quantile. Unpredictability of the exceedances is the DQ test's main criterion, i.e. the sequence of indicator functions $\left\{\mathrm{I}_{t}\right\}_{t=1, \ldots, T}$ is expected to be i.i.d. Table 6 in Appendix B shows the results using four lags of the $\mathrm{I}_{t}$ function as explanatory variable in the DQ test. Results are similar when varying the number of lags of $I_{t}$ that enter the DQ test. These results show that most CAViaR models are not rejected by the DQ test. However, the $25 \%$ and $75 \%$ quantiles for local currency returns appear to be less reliable. ${ }^{10}$ Several alternative CAViaR specifications are possible, e.g. asymmetric reactions to positive and negative returns (Engle and Manganelli, 2004) or an AR(1)-GARCH(1,1) specification (Kuester et al., 2006). However, these alternatives are inferior to the CAViaR model in Equation (3) using the DQ test as judging criterion.

\subsection{The model and empirical methodology}

This paper uses the gravity model of Beine and Candelon (2007) to analyze the annual bilateral co-exeedance probabilities calculated in Section 3.1 above. Define the general model as

$$
p_{i j, t}(\theta)=\beta_{1} p_{i j, t-1}(\theta)+\ldots+\beta_{m} p_{i j, t-m}(\theta)+\mathbf{X}_{\mathbf{i j}, \mathbf{t}}^{\prime} \gamma+\eta_{i j}+\sum_{t=2}^{T} \delta_{t} d_{t}+\epsilon_{i j, t}
$$

where $p_{i j, t}(\theta)$ is the co-exeedance probability between countries $i$ and $j$ at time t, $X_{i j, t}$ the matrix of exogenous variables, $\eta_{i j}$ a cross section dummy, $d_{t}$ a time dummy and $\epsilon_{i j, t}$ is the error term of the bilateral pair $i, j$ at time t. To simplify notation, from now on we assume that the value of $\theta$ has been fixed, and we drop the explicit dependance on $\theta$ of $p_{i j, t}$. With seventeen countries the cross sectional dimension consists of $\mathrm{N}=136$ bilateral relationships and the time dimension of $\mathrm{T}=32$ years, resulting in potentially 4352 observations.

The matrix of exogenous variables $X_{i j, t}$ aims to capture the channels through which shocks may be transmitted from one country to the other. The empirical counterparts of all variables in $X_{i j, t}$ are introduced in Section 4. This paper focuses on two particular channels of transmission related to

\footnotetext{
${ }^{10}$ See Section 4 for a discussion on returns denominated in local currencies or common currencies.
} 
integration.

Our first interest lies in the impact of financial integration. Through the finance channel investors are able to diversify and rebalance asset portfolios globally. The possibility of trading abroad allows investors to take benefit from investment opportunities. Since investors act globally, it might be expected that all markets will suffer more from global shocks. In this case, financial integration is likely to increase $p_{i j, t}$.

The second channel relates to trade integration. Trade patterns will affect business cycle fluctuations and hence stock market prices. If two countries trade extensively, it might be expected that their business cycles and their stock markets will be more correlated. The openness of one particular country to foreign trade can also act as a signalling device to international investors and lead them to buy domestic assets more extensively. Beine and Candelon (2007) find empirical evidence for that. This could strengthen the positive impact on $p_{i j, t}$.

In order to minimize the likelihood of misspecification, we also control for differences in industrial structures and for variations in exchange rates. The industrial composition of a country's stock market determines the extent to which countries face similar industry shocks. Oil companies in all countries react to a sharp rise in the oil price. If these firms have a strong weight in their countries' index, both indexes react similarly to this oil price shock. Consequently, the more similar two countries' industrial structure is, the more their stock market are likely to comove.

Other important controls are related to exchange rate movements. An investor prices currency risk and the price of this risk is determined by (expected) exchange rate movements. Exchange rate changes alter the return a foreign investor receives in his domestic currency. However, if currency risk is eliminated, e.g. through the introduction of the euro, the costs of rebalancing portfolios is lower. Moreover, exchange rate movements are not able to mitigate stock market movements anymore.

Following Beine and Candelon (2007) the model deals explicitly with unobserved heterogeneity by including cross section and time effects. In addition, since co-exeedance probabilities are potentially serially correlated, by including dynamics in the model it is possible to take care of serial dependence directly. Although a dynamic panel data model with cross section effects induces the famous Nickell (1981) bias, this bias is likely to be small 
due to the relatively large time dimension with respect to the cross section dimension.

The model is estimated using a FGLS approach taking care of potential heteroskedasticity. Due to the bilateral nature of the data cross section dependence is likely to be present. We use Panel Corrected Standard Errors, which are robust to cross-sectional dependence. However, Phillips and Sul (2007) argue that time effects reduce the bias induced by cross section dependence. ${ }^{11}$

\section{Data}

\subsection{Stock market returns}

In order to build the quantiles $q_{\theta t}$ and the measures of coexceedance $p_{i j, t}$, we first need to define the stock market returns. The sample consists of daily local currency denominated country stock market index returns from Thomson Datastream for 1974-2006, where daily returns are defined as $\mathrm{y}_{t}=$ $\ln \left(\mathrm{p}_{t}\right)-\ln \left(\mathrm{p}_{t-1}\right) .{ }^{12}$ There are 17 countries in the sample: Australia, Austria, Belgium, Canada, Denmark, France, Germany, Hong Kong, Ireland, Italy, Japan, Netherlands, South Africa, Singapore, Switzerland, United Kingdom and United States. Non trading days are excluded from the sample. ${ }^{13}$ To avoid problems of nonsynchronous trading we assume that the trading day starts in the US (t) and match this return with the one in the following

\footnotetext{
${ }^{11}$ Alternative estimation methods aim to correct explicitly for cross-section dependence by e.g. median unbiased estimation Phillips and Sul (2003) or imposing a factor structure Pesaran (2006). The correction by Phillips and Sul (2003) allows for dynamics, but is only valid assuming $\mathrm{T} \rightarrow \infty$ and the impact of including exogenous regressors is unclear. Exogenous regressors are included in the correction by Pesaran (2006), however dynamics cannot be included explicitly resulting in biases due to autocorrelation. GMM based estimation does not suffer from the Nickell (1981) bias and is robust to potential endogeneity. However, a main disadvantage of GMM is the appropriate selection of an instrument set. Since potentially many different instrument sets are possible (i.e. not rejected by the Sargan test), estimations results turn out to be very unstable across valid instrument sets.

${ }^{12}$ Stock market returns can either be denominated in local currencies or in a common currency (usually US\$). Several authors advocate the use of local currency returns (Cappiello et al., 2005; Fratzscher, 2002; Hartmann et al., 2004), whereas others (Bekaert et al., 2008; Brooks and Del Negro, 2004) prefer common currency denominated returns. This paper opts for local currency returns because the use of common currency returns "may also introduce a bias in that a high degree of integration may simply be due to a similarity in exchange rate changes rather than direct financial integration" (Fratzscher, 2002, p. 191). Moreover, taking all returns in US\$ implicitly assumes investors are not able to hedge currency risk.

${ }^{13}$ For a comprehensive list of all excluded days consult Appendix C.
} 
day in Asia, Africa and Europe $(\mathrm{t}+1)$. The underlying assumption is that all (or most) news is generated in the US (North America) and spreads one calendar day later to Asia, Africa and Europe.

Table 1 presents some descriptive statistics of the stock market index series used. There is some variation in the average daily return, with the lowest return in Japan (0.023\%) and the highest in South Africa (0.061\%). This implies that returns in South Africa are about three times as high as in Japan. However, part of this difference can be explained by different inflation rates in both countries, since returns are denominated in local currencies.

One might expect that these countries also have the lowest and highest volatility, but this turns out not to be the case. The lowest volatility is observed in the Austrian market $(0.797 \%)$, whereas the highest is in Hong Kong $(1.682 \%)$. Hence, the volatility in Hong Kong is more than twice that in Austria.

Table 1: Descriptive statistics of equity return: daily data, 1/1/1974$31 / 12 / 2006$

\begin{tabular}{l|ccccc}
\hline \hline country & $\begin{array}{c}\text { avg return } \\
\text { \% per day })\end{array}$ & $\begin{array}{c}\text { st. deviation } \\
\text { (\% per day })\end{array}$ & skewness & kurtosis & $\begin{array}{c}\text { normality test } \\
(\text { Chi2) }\end{array}$ \\
\hline Australia & 0.038 & 1.046 & -2.79 & 83.12 & $6724.6^{* * *}$ \\
Austria & 0.033 & 0.797 & -0.30 & 18.83 & $1993.9^{* * *}$ \\
Belgium & 0.029 & 0.850 & -0.44 & 16.09 & $1956.6^{* * *}$ \\
Canada & 0.032 & 0.821 & -0.79 & 16.92 & $2459.8^{* * *}$ \\
Denmark & 0.042 & 0.944 & -0.94 & 36.50 & $3407.4^{* * *}$ \\
France & 0.038 & 1.135 & -0.37 & 7.86 & $1093.8^{* * *}$ \\
Germany & 0.028 & 0.993 & -0.66 & 11.08 & $1819.1^{* * *}$ \\
Hong Kong & 0.048 & 1.682 & -2.34 & 57.93 & $5861.6^{* * *}$ \\
Ireland & 0.047 & 1.067 & -0.40 & 18.97 & $2088.3^{* * *}$ \\
Italy & 0.039 & 1.312 & -0.26 & 7.92 & $1015.2^{* * *}$ \\
Japan & 0.023 & 1.031 & -0.36 & 15.09 & $1807.6^{* * *}$ \\
Netherlands & 0.033 & 1.018 & -0.32 & 9.77 & $1301.8^{* * *}$ \\
South Africa & 0.061 & 1.291 & -0.74 & 12.87 & $2091.7^{* * *}$ \\
Singapore & 0.026 & 1.279 & -1.00 & 35.72 & $3490.2^{* * *}$ \\
Switzerland & 0.032 & 0.890 & -0.98 & 18.53 & $2831.2^{* * *}$ \\
United Kingdom & 0.039 & 1.031 & -0.25 & 11.35 & $1417.4^{* * *}$ \\
United States & 0.033 & 0.982 & -1.20 & 30.82 & $3660.7^{* * *}$ \\
\hline \hline
\end{tabular}

Stock market data is daily local currency denominated. The test for normality is based on D'Agostino et al. (1990). *** implies rejection at the $1 \%$ level.

All countries face significant negative skewness, indicating lower tails. Moreover, skewness is significantly larger than 3, which corresponds to the normal distribution. Excess skewness implies that the distributions have 
fat tails. Normality is strongly reject for all series, indicating that any assumption of normally distributed returns is not valid.

\subsection{Financial Liberalization}

Several indicators are available to measure the degree of financial openness of an economy. The most detailed indicator in terms of disaggregation and coverage across time and countries is the KAOPEN developed by Chinn and Itô (2002). For each country, the value of KAOPEN is constructed from four categories of financial openness in the IMF's Annual Report on Exchange Arrangements and Exchange Restrictions: 1) The presence of multiple exchange rates, 2) restrictions on current account restrictions, 3) restrictions on capital account restrictions and 4) Requirement or surrender of export proceeds. ${ }^{14}$ The larger KAOPEN is, the more financially open a country is.

A bilateral measure needs to be constructed since KAOPEN (and other alternatives) are indicators for a single country. Define the bilateral indicator of financial liberalization as

$$
\text { financial liberalization }{ }_{i j, t}=\min \left(K A O P E N_{i, t}, K A O P E N_{j, t}\right) \text {, }
$$

where financial liberalization ${ }_{i j, t}$ has the value of the least open country.

Another traditional measure to capture financial liberalization is the IMF Dummy, where a value of 1 implies that a country has capital account restrictions in force and 0 implies no restrictions. The main advantage of the KAOPEN measure is its higher disaggregation (theoretically it can take on infinitely many values) than the IMF dummy. Alternatives with higher disaggregation than the IMF Dummy include indicators by Quinn (1997) and Miniane (2004). However, both indicators are available only for a limited number of countries and for a limited time span. The data on KAOPEN is retrieved from Hiro Itô's website.

\subsection{Trade Integration}

The first indicator of trade integration is based on the measure of trade competition by Glick and Rose (1999) and aims to assess the extent to

\footnotetext{
${ }^{14}$ Consult Chinn and Itô (2002) and Hiro Itô's website for more details on construction of this variable.
} 
which two countries compete in the same export markets. If two countries compete in the same export markets it seems reasonable that both countries' stock markets react similarly to shocks originating in these export markets.

The trade competition indicator of Glick and Rose (1999) is given by

$$
\text { trade competition }_{i j, t}=\sum_{1}^{k} \frac{x_{i k, t}+x_{j k, t}}{x_{i, t}+x_{j, t}} *\left(1-\frac{x_{i k, t} / x_{i, t}-x_{j k, t} / x_{j, t}}{x_{i k, t} / x_{i, t}+x_{j k, t} / x_{j, t}}\right) \text {, }
$$

where $x_{i k, t}$ represents exports from country i to country $\mathrm{k}$ at time $t$ and $\mathrm{x}_{i, t}$ and $\mathrm{x}_{j, t}$ represent total exports of countries $\mathrm{i}$ and $\mathrm{j}$ respectively. The countries considered in $\mathrm{k}$ are all the countries in the sample and the rest of the world, except for $\mathrm{i}$ and $\mathrm{j}$. This measure increases as export patterns become more similar and is weighted by the joint importance of the export market considered.

The second indicator of trade integration aims at measuring the strength of direct trade between two countries. In order to determine the strength of a bilateral trade relationship, we use the indicator constructed by Frankel and Rose (1998):

$$
\text { bilateral trade } \operatorname{trj,t}=\frac{X_{i j, t}+M_{i j, t}}{G D P_{i ., t}+G D P_{j, t}},
$$

where $\mathrm{X}$ and $\mathrm{M}$ are nominal USD exports and imports respectively and GDP is nominal GDP in USD. This measure increases as bilateral trade becomes more important relative to GDP. In other terms, the indicator increases if bilateral trade grows faster than GDP. Trade data is extracted from the IMF's Direction of Trade Statistics and GDP data from the World Bank World Economic Indidicators.

\subsection{Industrial Structure}

Stock market indexes are more likely to comove if these have a similar industrial structure, since global industry specific shocks are transmitted to both countries. Industry structure data on Datastream stock market indexes are not directly available. As an alternative, industry value added data is used to determine the production structure of a country. The underlying assumption is that a country's production structure is reflected in the stock market industry composition. To determine the similarity of two countries' produc- 
tion structure the specialization indicator by Krugman (1991) is used. ${ }^{15} \mathrm{We}$ compute this indicator of industrial difference by summing up the absolute value of the difference of an industry's GDP share in two countries:

$$
\text { specialization }_{i j, t}=\sum_{1}^{N}\left|s_{n, i, t}-s_{n, j, t}\right|,
$$

where $s_{n, i, t}$ is the GDP share of industry $n$ in country $i$ or $j$ at time t. There are $\mathrm{N}=9$ industries considered in the specialization index, using value added data from the EU KLEMS database and other datasets for non-EU countries. ${ }^{16}$

\subsection{Exchange Rate Volatility}

Exchange rate volatility is calculated using the methodology of realized volatility by Andersen et al. (2003). Daily returns are used to calculate annual volatility by

$$
\text { exchange rate volatility }_{i j, t}=\sum_{d=1}^{D_{t}}\left[r_{t, d}^{i j}\right]^{2},
$$

with $\mathrm{r}$ being the exchange rate return at day $\mathrm{d}$ and $\mathrm{D}$ represents the number of trading days in one year. Bilateral exchange volatility is calculated using exchange rate data from Datastream.

Several countries in the sample are EMU member and introduced the euro in 1999. This implies that exchange rate volatilities for EMU country pairs is zero since 1999. To consider the effect of the introduction of the euro separately a dummy variable called EMU is introduced. This variable is one as of 1999 for all pairs consisting of two countries using the euro as legal tender.

\footnotetext{
${ }^{15}$ This indicator is used in the business cycle literature by e.g. Clark and van Wincoop (2001).

${ }^{16}$ Details about all databases is provided in Appendix A.
} 


\section{Results}

\subsection{Baseline results}

The baseline results use the model in equation (4) and the full set of explanatory variables from section 4. All estimations are effectively from 1974 until 2005 due to the availability of industry data only until 2005. For each quantile the autoregressive order in (4) is determined by adding enough lags of $p_{i j, t}$ to get rid of serial correlation. Cross-section and time dummies are not reported for the sake of brevity. A first observation from Table 2 is the strong serial dependence of codependence probabilities. For the $10 \%$ and $90 \%$ quantiles up to three lags are added to remove all serial correlation. The middle quantiles have two lags, but note that the coefficients on these lags are relatively high, i.e. the sum of the coefficients on the lagged dependent variable is close to 0.5 .

A first important implication of our results is that integration exerts asymmetric effects on comovement. For a couple of variables that capture integration, we find evidence of asymmetric effects in the sense that the change in the comovement of stock market returns depends on the part of the return distribution. In particular, financial integration is found to increase comovement in all parts of the return distribution but with different magnitudes.

Interestingly financial openness tends to increase comovement more in periods of bad returns for both stock markets. This finding relates to the contagion literature, where financial crisis spread quickly from one country to the other (See e.g. Forbes and Rigobon, 2002). Hence, the scope for portfolio diversification tends to decrease at times when it is much more needed. This might be called the dark side of financial integration.

The economic magnitude of the coefficient on financial liberalization is quite important. The difference between a very open and very closed economy is five units. With a coefficient of 0.010 on the $5 \%$ quantile, this implies that the coexeedance probability increases by about five percentage points if a country liberalizes. A transition from closed to fully open is a change from -2.5 to 2.5 in the KAOPEN indicator.

Asymmetric effects are also reflected by the fact that some variables tend to affect comovements only when returns evolve in a particular area of the return distribution. It is the case for trade integration captured by bilateral 
Table 2: Explaining codependence local returns (Baseline specification)

\begin{tabular}{l|cccccc}
\hline \hline & Q5 & Q10 & Q25 & Q75 & Q90 & Q95 \\
lagged probability (-1) & $0.125^{* * *}$ & $0.196^{* * *}$ & $0.348^{* * *}$ & $0.294^{* * *}$ & $0.178^{* * *}$ & $0.098^{* *}$ \\
& $(0.042)$ & $(0.044)$ & $(0.041)$ & $(0.042)$ & $(0.043)$ & $(0.041)$ \\
lagged probability (-2) & $0.075^{*}$ & $0.093^{* *}$ & $0.143^{* * *}$ & $0.133^{* * *}$ & $0.132^{* * *}$ & \\
& $(0.041)$ & $(0.043)$ & $(0.041)$ & $(0.041)$ & $(0.042)$ & \\
lagged probability (-3) & & $0.099^{* *}$ & & & $0.085^{* *}$ & \\
& & $(0.039)$ & & & $(0.042)$ & \\
trade competition & $0.151^{*}$ & $0.127^{*}$ & $0.196^{* * *}$ & $0.163^{* * *}$ & $0.184^{* * *}$ & $0.127^{* *}$ \\
& $(0.088)$ & $(0.074)$ & $(0.048)$ & $(0.047)$ & $(0.062)$ & $(0.061)$ \\
bilateral trade & 0.592 & 1.135 & 0.672 & $1.707^{* * *}$ & 0.964 & 1.203 \\
& $(0.949)$ & $(0.956)$ & $(0.694)$ & $(0.658)$ & $(0.752)$ & $(0.926)$ \\
financial liberalization & $0.010^{* * *}$ & $0.009^{* * *}$ & $0.007^{* * *}$ & $0.007^{* * *}$ & 0.003 & $0.007^{* * *}$ \\
& $(0.003)$ & $(0.003)$ & $(0.002)$ & $(0.003)$ & $(0.003)$ & $(0.002)$ \\
industrial dissimilarity & $-0.110^{*}$ & $-0.119^{* * *}$ & $-0.060^{*}$ & -0.051 & $-0.109^{* * *}$ & $-0.097^{* *}$ \\
& $(0.057)$ & $(0.044)$ & $(0.035)$ & $(0.033)$ & $(0.038)$ & $(0.042)$ \\
exchange rate volatility & $-0.318^{* * *}$ & $-0.286^{* *}$ & $-0.158^{*}$ & -0.096 & -0.152 & -0.074 \\
& $(0.121)$ & $(0.112)$ & $(0.082)$ & $(0.083)$ & $(0.100)$ & $(0.084)$ \\
joint EMU membership & $0.069^{* * *}$ & $0.047^{* *}$ & $0.038^{* * *}$ & $0.064^{* * *}$ & $0.076^{* * *}$ & $0.117^{* * *}$ \\
& $(0.021)$ & $(0.018)$ & $(0.014)$ & $(0.016)$ & $(0.017)$ & $(0.015)$ \\
\hline \hline Number obs & 3566 & 3488 & 3566 & 3566 & 3488 & 3644 \\
R2 & 0.49 & 0.64 & 0.82 & 0.70 & 0.46 & 0.30 \\
Hausman test (p-value) & 0.000 & 0.000 & 0.000 & 0.000 & 0.000 & 0.000 \\
Wald test (p-value) & 0.000 & 0.000 & 0.000 & 0.000 & 0.000 & 0.000 \\
Wooldridge test (p-value) & 0.537 & 0.500 & 0.061 & 0.219 & 0.534 & 0.120 \\
Friedman test (p-value) & 1.000 & 1.000 & 1.000 & 1.000 & 1.000 & 1.000 \\
abs off-diagonal elements & 0.244 & 0.241 & 0.247 & 0.246 & 0.240 & 0.238 \\
Frees (Q-statistic) & $1.356^{* * *}$ & $1.143^{* * *}$ & $1.773^{* * *}$ & $1.728^{* * *}$ & $1.315^{* * *}$ & $0.851^{* * *}$ \\
\hline \hline
\end{tabular}

FGLS cross section weights, fixed cross-section effect, iterative elimination of common time shocks and Panel Corrected Standard Errors (SUR). The critical values of the Frees test are: $10 \%=0.413,5 \%=0.568$ and $1 \%=0.903$.

trade intensity and trade competition. Trade is found to affect comovement when returns are in the central part of the distribution but not when these returns are in the far upper and lower tail.

The impact of industrial structure seems to exhibit symmetric effects. A negative sign implies that the more dissimilar countries are the lower is their comovement, confirming the findings of Roll (1992) that industrial composition is an important determinant to explain stock market comovement. Our results show that for both negative and positive industry news these effects are present.

A decrease in exchange rate volatility is found to increase stock market comovement strongly for the lower tail. This implies that stable exchange rates increase the occurrence of joint negative extreme events. The European monetary integration process also favored the correlation between 
European stock market. Fratzscher (2002) studies the effect of EMU on European stock market comovement using a trivariate GARCH model with time varying coefficients and finds that the elimination of exchange rate volatility increases inter EMU stock market comovement strongly. These variables are found to act as important controls and ensure that model (4) does not suffer from important specification bias due to omitted variables.

The economic impact of EMU is large, ranging from a 3.8 percentage point increase in coexeedance for Q25 to 11.7 percentage points for Q95. This increase in comovement lowers the diversification potential for investors significantly within the European Monetary Union. A 10\% increase in exchange rate volatility results in a 3.18\% decrease in comovement for Q5 and $2.86 \%$ for Q10. For Q25 it is only marginally significant and the effect is insignificant for the other quantiles.

We conduct several specification checks to investigate the appropriateness of the empirical approach. First, we apply the Hausman test to decide on the use of fixed or random cross section effects. The results in Table 2 clearly show that random effects are strongly rejected in favor of a fixed effects specification. Next, we test for the presence of heteroskedasticity in the residuals to justify the GLS approach. The test is on a fixed effects specification without GLS weights. Table 2 shows that the Wald test strongly rejects homoskedasticity of the residuals, i.e. it justifies the GLS approach. The number of lags of the dependent variable need to be sufficient to eliminate residual serial correlation. We apply the Wooldridge test for this purpose and conclude that serial correlation appears to be eliminated by the dynamics in the model.

In order to test for cross-section dependence the Friedman and Frees tests are applied. The Friedman test does not reject the assumption of cross-section independence. We also use the Pesaran test and its results are identical to those of the Friedman test. It seems very unlikely that there is cross-sectional dependence present.

However, De Hoyos and Sarafidis (2006) point out that the Friedman and Pesaran tests are biased in cases where cross-sectional dependence is characterized by alternating correlations in the residuals. The Pesaran test suffers from the same weakness. Indeed, the average absolute correlations are all around 0.24 , which is relatively high. Frees' test is not subject to this drawback and this test strongly rejects the assumption of cross-sectional 
independence. Consequently, Panel Corrected Standard Errors are necessary to deal with the issue of cross sectional dependence.

Interestingly, the failure to disentangle the impact (for instance by using the correlation as the dependent variable) leads to underestimate the impact of trade and financial integration on stock market comovement. To illustrate this, Table 3 reports the estimate of the same model, using realized correlation as dependent variable instead of $p_{i j, t}$. The estimation of such a model fails to capture the positive impact of trade variables on the comovement of stock markets.

Table 3: Explaining codependence local returns (Realized correlation)

\begin{tabular}{l|cc}
\hline \hline & Realized correlation & FZ-transform \\
lagged correlation (-1) & $0.362^{* * *}$ & $0.440^{* * *}$ \\
& $(0.042)$ & $(0.049)$ \\
lagged correlation (-2) & $0.113^{* *}$ & $0.143^{* * *}$ \\
& $(0.047)$ & $(0.048)$ \\
lagged correlation (-3) & $0.132^{* * *}$ & \\
& $(0.048)$ & $0.438^{*}$ \\
trade competition & 0.146 & $(0.233)$ \\
& $(0.101)$ & 3.310 \\
bilateral trade & 1.356 & $(3.026)$ \\
& $(1.101)$ & $0.019^{*}$ \\
financial liberalization & $0.011^{* * *}$ & $(0.010)$ \\
& $(0.004)$ & $-0.400^{* * *}$ \\
industrial dissimilarity & $-0.185^{* * *}$ & $(0.155)$ \\
& $(0.067)$ & $-0.932^{* * *}$ \\
exchange rate volatility & $-0.555^{* * *}$ & $(0.355)$ \\
& $(0.160)$ & $0.183^{* * *}$ \\
joint EMU membership & $0.037^{*}$ & $(0.060)$ \\
& $(0.020)$ & 3566 \\
\hline \hline Number obs & 3488 & 0.78 \\
R2 & 0.85 & \\
\hline \hline
\end{tabular}

Another illustration of these asymmetric effect is illustrated by the impact of the industrial similarity between the two countries. Countries with similar industrial structures have more correlated stock markets only in the "far" tails, as reflected by the impact on the $Q 5, Q 10, Q 90$ and $Q 95$ quantiles. Of course, this cannot be accounted for with a traditional analysis involving correlations.

Moreover, the results show that financial liberalization has a strong positive impact, but do not show that the effect is different across the return distribution. The estimated results in column 1 do not show any impact of 
EMU, which seems an awkward finding since this variable is highly significant in Table 2.

A possible critique on the correlation measure is its boundedness between -1 and 1, which may lead to interpretation difficulties if the estimated variables are outside this range. When we apply the FisherZ transform

$$
\rho_{i j t}^{F Z}=\ln \left(\frac{1+\rho_{i j t}}{1-\rho_{i j t}}\right)
$$

where $\rho_{i j t}$ is the correlation coefficient for countries $\mathrm{i}$ and $\mathrm{j}$ at time t, correlation is mapped into the $(-\infty, \infty)$ domain and these problems do not arise. However, the disadvantage is that we cannot determine the economic impact of the coefficient values.

The second column in Table 3 shows the results if we use the Fisher-Z transform. Most results seem to be robust, but there are some important differences with the first column. First, the lag structure of the dependent variable changes. Second, trade competition is now marginally significant. This variables is highly significant in Table 2 for certain quantiles more in the center of the return distribution. Third, the EMU variable becomes highly significant, which seems reasonable from previous results. However, note that results are quite sensitive to the use of the Fisher-Z transformation.

\subsection{Robustness}

In the previous section we compare the baseline model to estimates from using realized correlation. We also report the results for the Fisher-Z transform of correlation and find that the statistical significance of some variables changes quite severely. Since the codependence probability is bounded between zero and one it seems reasonable to map this variable as well to the $(-\infty, \infty)$ domain. A logistic transformation seems straightforward, but cannot be executed. Some observations have a zero value and this is mapped into $-\infty$.

An alternative approach is to use the Fisher-Z transformation as well for the codependence probabilities. The resulting estimates are presented in Table 4. However, as probabilities are limited between zero and one, these are not mapped into the domain $(-\infty, \infty)$, but into $(0, \infty)$, which is only unbounded on one side.

Naturally the coefficient values change, but notice the strong correspon- 
Table 4: Explaining codependence local returns (Fisher-Z transformation).

\begin{tabular}{l|cccccc}
\hline \hline \multirow{3}{*}{ lagged probability (-1) } & Q5 & Q10 & Q25 & Q75 & Q90 & Q95 \\
& $0.134^{* * *}$ & $0.207^{* * *}$ & $0.392^{* * *}$ & $0.303^{* * *}$ & $0.188^{* * *}$ & $0.106^{* *}$ \\
& $(0.043)$ & $(0.045)$ & $(0.043)$ & $(0.043)$ & $(0.044)$ & $(0.042)$ \\
lagged probability (-2) & $0.077^{*}$ & $0.099^{* *}$ & $0.103^{* *}$ & $0.136^{* * *}$ & $0.122^{* * *}$ & $(0.041)$ \\
& $(0.042)$ & $(0.044)$ & $(0.042)$ & $(0.042)$ & \multicolumn{3}{c}{$0.088^{* *}$} \\
lagged probability (-3) & & $0.105^{* * *}$ & & & $(0.042)$ \\
& & $(0.040)$ & & & \\
trade competition & $0.314^{*}$ & $0.277^{*}$ & $0.462^{* * *}$ & $0.383^{* * *}$ & $0.391^{* * *}$ & $0.294^{* *}$ \\
& $(0.186)$ & $(0.161)$ & $(0.118)$ & $(0.110)$ & $(0.124)$ & $(0.132)$ \\
bilateral trade & 0.999 & 2.781 & 1.557 & $4.188^{* *}$ & 1.872 & 2.407 \\
financial liberalization & $(2.080)$ & $(2.193)$ & $(1.728)$ & $(1.660)$ & $(1.591)$ & $(1.968)$ \\
& $0.019^{* * *}$ & $0.018^{* * *}$ & $0.014^{* *}$ & $0.014^{* *}$ & 0.001 & $0.013^{* *}$ \\
industrial dissimilarity & $(0.007)$ & $(0.007)$ & $(0.006)$ & $(0.006)$ & $(0.005)$ & $(0.005)$ \\
& $-0.213^{*}$ & $-0.247^{* *}$ & -0.132 & -0.108 & $-0.213^{* * *}$ & $-0.177^{* *}$ \\
exchange rate volatility & $(0.123)$ & $(0.099)$ & $(0.084)$ & $(0.078)$ & $(0.080)$ & $(0.088)$ \\
& $-0.637^{* *}$ & $-0.642^{* * *}$ & $-0.344^{*}$ & -0.206 & -0.226 & -0.140 \\
joint EMU membership & $(0.260)$ & $(0.241)$ & $(0.194)$ & $(0.197)$ & $(0.194)$ & $(0.187)$ \\
& $0.163^{* * *}$ & $0.111^{* * *}$ & $0.108^{* * *}$ & $0.169^{* * *}$ & $0.181^{* * *}$ & $0.254^{* * *}$ \\
& $(0.048)$ & $(0.043)$ & $(0.037)$ & $(0.041)$ & $(0.037)$ & $(0.033)$ \\
\hline \hline Number obs & 3566 & 3488 & 3566 & 3566 & 3488 & 3644 \\
R2 & 0.45 & 0.60 & 0.77 & 0.68 & 0.43 & 0.28 \\
\hline \hline
\end{tabular}

dence between Table 4 and Table 2. First, we confirm that trade integration has its strongest impact on the middle quantiles. Second, financial liberalization has a significant positive impact across most quantiles, but the effect is strongest on the lower quantiles. Third, the patterns of exchange rate volatility and joint EMU membership are identical, the former impacts mostly the lower tail, whereas the latter has the largest impact on the upper tail.

The disadvantage of the Fisher- $\mathrm{Z}$ transformation is the difficulty to interpret the magnitude of the coefficients. An important advantage of using the probabilities in the domain $[0,1]$ is the possibility to judge on economic significance, instead of statistical significance only.

Another robustness check is to use an alternative measure of financial integration. We use the IMF capital accounts liberalization dummy instead of the bilateral measures built from the KAOPEN variable of Chinn and Itô (2002). Table 5 reports the results obtained with this alternative measure.

The results are virtually identical to those from the KAOPEN measure, both for the financial integration variable and the other determinants of comovement. Comparing Table 5 with Table 2 shows exactly how robust 
Table 5: Explaining codependence local returns (IMF Dummy).

\begin{tabular}{l|cccccc}
\hline \hline \multirow{3}{*}{ lagged probability (-1) } & Q5 & Q10 & Q25 & Q75 & Q90 & Q95 \\
& $0.127^{* * *}$ & $0.198^{* * *}$ & $0.358^{* * *}$ & $0.299^{* * *}$ & $0.176^{* * *}$ & $0.097^{* *}$ \\
& $(0.042)$ & $(0.044)$ & $(0.040)$ & $(0.042)$ & $(0.043)$ & $(0.041)$ \\
lagged probability (-2) & $0.080^{*}$ & $0.100^{* *}$ & $0.144^{* * *}$ & $0.135^{* * *}$ & $0.119^{* * *}$ & \\
& $(0.041)$ & $(0.043)$ & $(0.042)$ & $(0.041)$ & $(0.040)$ & \\
lagged probability (-3) & & $0.107^{* * *}$ & & & $0.083^{* *}$ \\
& & $(0.039)$ & & & $(0.041)$ \\
trade competition & $0.144^{*}$ & $0.140^{*}$ & $0.191^{* * *}$ & $0.160^{* * *}$ & $0.185^{* * *}$ & $0.135^{* *}$ \\
bilateral trade & $(0.087)$ & $(0.074)$ & $(0.049)$ & $(0.047)$ & $(0.058)$ & $(0.062)$ \\
financial liberalization & 0.490 & 1.055 & 0.714 & $1.739^{* * *}$ & 0.953 & 1.124 \\
(IMF Dummy) & $(0.947)$ & $(0.954)$ & $(0.699)$ & $(0.662)$ & $(0.742)$ & $(0.913)$ \\
industrial dissimilarity & $-0.019^{* *}$ & $-0.019^{* *}$ & $-0.012^{* *}$ & $-0.013^{* *}$ & -0.003 & $-0.023^{* * *}$ \\
& $(0.009)$ & $(0.008)$ & $(0.006)$ & $(0.006)$ & $(0.006)$ & $(0.006)$ \\
exchange rate volatility & $-0.115^{* *}$ & $-0.123^{* * *}$ & $-0.065^{*}$ & -0.053 & $-0.106^{* * *}$ & $-0.110^{* * *}$ \\
& $(0.057)$ & $(0.045)$ & $(0.036)$ & $(0.033)$ & $(0.038)$ & $(0.042)$ \\
& $-0.313^{* *}$ & $-0.294^{* * *}$ & $-0.156^{*}$ & -0.095 & -0.110 & -0.074 \\
joint EMU membership & $(0.124)$ & $(0.110)$ & $(0.082)$ & $(0.084)$ & $(0.092)$ & $(0.084)$ \\
& $0.073^{* * *}$ & $0.048^{* * *}$ & $0.039^{* * *}$ & $0.066^{* * *}$ & $0.080^{* * *}$ & $0.117^{* * *}$ \\
& $(0.021)$ & $(0.018)$ & $(0.015)$ & $(0.017)$ & $(0.017)$ & $(0.015)$ \\
\hline \hline Number obs & 3566 & 3488 & 3566 & 3566 & 3488 & 3644 \\
R2 & 0.49 & 0.63 & 0.81 & 0.70 & 0.46 & 0.30 \\
\hline \hline
\end{tabular}

the results are. First, note that the coefficients on the lagged dependent variable and the explanatory variables change minimally. Second, the IMF dummy variable confirms that the strongest effect of financial liberalization is on the lower tail.

Note that financial liberalization is not significant for the $90 \%$ quantile, but highly significant for the $95 \%$ quantile. We do not have a explanation for this pattern, however one has to realize that the IMF dummy is a very simplistic variable proxying financial liberalization and it has its limitations. However, the more disaggregated KAOPEN variable shows the same pattern for financial liberalization showing the close correspondence between both variables.

The results are robust to the inclusion of inflation rates in the estimation. Using local currency possibly might suggest a role for inflation differences, but this turns out not to be the case. Inflation differences are never significant for all estimated quantiles. ${ }^{17}$

Next, we investigate if interest rate differences explain coexeedance prob-

\footnotetext{
${ }^{17}$ These results are not reported but are available upon request.
} 
abilities. Define interest rate differentials as

$$
\text { interest rate } \operatorname{diff}_{i j t}=\frac{1}{13} \sum_{m=1}^{13}\left|I_{i t, m}-I_{j t, m}\right|,
$$

where $I_{i t, m}$ and $I_{j t, m}$ are the short term interest rates from Jan-1 until Dec31 at the monthly frequency for countries $i$ and $j$ respectively.

Table 6: Explaining codependence local returns (Interest rates).

\begin{tabular}{l|cccccc}
\hline \hline \multirow{3}{*}{ lagged probability (-1) } & Q5 & Q10 & Q25 & Q75 & Q90 & Q95 \\
& $0.125^{* * *}$ & $0.196^{* * *}$ & $0.349^{* * *}$ & $0.292^{* * *}$ & $0.176^{* * *}$ & $0.095^{* *}$ \\
& $(0.042)$ & $(0.044)$ & $(0.041)$ & $(0.042)$ & $(0.043)$ & $(0.041)$ \\
lagged probability (-2) & $0.075^{*}$ & $0.093^{* *}$ & $0.141^{* * *}$ & $0.133^{* * *}$ & $0.118^{* * *}$ & \\
& $(0.041)$ & $(0.043)$ & $(0.041)$ & $(0.041)$ & $(0.040)$ & \\
lagged probability (-3) & & $0.100^{* *}$ & & & $0.082^{* *}$ & \\
& & $(0.039)$ & & & $(0.041)$ & \\
trade competition & $0.148^{*}$ & $0.127^{*}$ & $0.191^{* * *}$ & $0.163^{* * *}$ & $0.187^{* * *}$ & $0.131^{* *}$ \\
& $(0.088)$ & $(0.074)$ & $(0.048)$ & $(0.047)$ & $(0.059)$ & $(0.061)$ \\
bilateral trade & 0.617 & 1.134 & 0.733 & $1.737^{* * *}$ & 0.947 & 1.051 \\
financial liberalization & $(0.951)$ & $(0.956)$ & $(0.697)$ & $(0.662)$ & $(0.746)$ & $(0.925)$ \\
& $0.011^{* * *}$ & $0.009^{* * *}$ & $0.008^{* * *}$ & $0.008^{* * *}$ & 0.001 & $0.005^{* *}$ \\
industrial dissimilarity & $(0.003)$ & $(0.003)$ & $(0.002)$ & $(0.002)$ & $(0.003)$ & $(0.002)$ \\
& $-0.111^{*}$ & $-0.119 * * *$ & $-0.060^{*}$ & -0.049 & $-0.106^{* * *}$ & $-0.098^{* *}$ \\
exchange rate volatility & $(0.057)$ & $(0.045)$ & $(0.035)$ & $(0.033)$ & $(0.038)$ & $(0.042)$ \\
& $-0.334^{* * *}$ & $-0.288^{* *}$ & $-0.175^{* *}$ & -0.118 & -0.099 & -0.008 \\
joint EMU membership & $(0.122)$ & $(0.114)$ & $(0.081)$ & $(0.085)$ & $(0.094)$ & $(0.090)$ \\
& $0.069^{* * *}$ & $0.047^{* *}$ & $0.038^{* * *}$ & $0.064^{* * *}$ & $0.081^{* * *}$ & $0.120^{* * *}$ \\
interest rate differential & $(0.021)$ & $(0.018)$ & $(0.015)$ & $(0.017)$ & $(0.017)$ & $(0.015)$ \\
& 0.110 & 0.015 & 0.134 & 0.148 & -0.069 & $-0.281^{* * *}$ \\
& $(0.149)$ & $(0.123)$ & $(0.098)$ & $(0.103)$ & $(0.110)$ & $(0.106)$ \\
\hline \hline Number obs & 3566 & 3488 & 3566 & 3566 & 3488 & 3644 \\
R2 & 0.49 & 0.64 & 0.82 & 0.70 & 0.46 & 0.30 \\
\hline \hline
\end{tabular}

FGLS cross section weights, fixed cross-section effect, iterative elimination of common time shocks and Panel Corrected Standard Errors (SUR).

Table 6 shows the results if we add the interest rate differential to the specification. This variable is only significant for the Q95 estimation. However, the correlation between exchange rate volatility and interest rate differential is about 0.37 , suggesting that some multicollinearity problems potentially arise. It seems that both variables capture partially the same effects, e.g. because both exchange rate volatility and interest differentials capture monetary phenomena. To avoid potential multicollinearity problems we present our baseline specification without interest rate differentials. 


\section{Conclusion}

In conclusion, this paper shows the asymmetric impact of global integration processes on stock market comovement at different parts of the return distribution. We measure comovement by estimating coexeendance probabilities using the methodology of Cappiello et al. (2005). These coexeedance probabilities are analyzed in a gravity model using bilateral trade, finance, industry and exchange rate indicators.

Our findings suggest that the global integration process has asymmetric effects on comovement at different parts of the return distribution. First, trade integration only marginally impacts lower tail comovement, but does have a strong effect on comovement for the more central quantiles. Second, financial liberalization has a strong impact throughout the return distribution. However, its effects are stronger on the left tail of the distribution. Finally, a decrease in exchange rate volatility has a strong positive impact on lower tail comovement. Once exchange rate volatility is eliminated by e.g. the introduction of the euro, this has a strong effect on comovement as well, but especially on the upper tail.

The increase in comovements due to the global integration process illustrate the dark side of global integration. Investors will experience more difficulties in reaping the gains from asset diversification, especially diversification in bad times will become more challenging. 


\section{References}

Andersen, T., Bollerslev, T., Diebold, F. and Labys, P. (2003). Modeling and forecasting realized volatility, Econometrica 71(2): 579-625.

Anderson, J. and Van Wincoop, E. (2004). Trade costs, Journal of Economic Literature XLII(September 2004): 691-751.

Bae, K.-H., Karolyi, A. and Stulz, R. (2003). A new approach to measuring financial contagion, The Review of Financial Studies 16(3): 717-763.

Beine, M. and Candelon, B. (2007). Liberalization and stock market comovement between emerging economies, CESifo Working Paper No. 2131.

Bekaert, G. and Harvey, C. (1995). Time-varying world integration, The Journal of Finance $\mathbf{L}(2)$ : 403-444.

Bekaert, G. and Harvey, C. (2000). Foreign speculators and emerging equity markets, The Journal of Finance $\mathbf{L V}(2)$ : 565-614.

Bekaert, G., Harvey, C. and Lundblad, C. (2005). Does financial liberalization spur growth, Journal of Financial Economics 77: 3-55.

Bekaert, G., Hodrick, R. and Zhang, X. (2008). International stock return comovements, Working Paper .

Brooks, R. and Del Negro, M. (2004). The rise in comovement across national stock markets: market integration or it bubble?, Journal of Empirical Finance 11: 659-680.

Cappiello, L., Gerard, B. and Manganelli, S. (2005). Measuring comovements by regression quantiles, ECB Working Paper No. 501 (July 2005)

Chinn, M. and Forbes, K. (2004). A decomposition of global linkages in financial markets over time, The Review of Economics and Statistics 86(3): 705-722.

Chinn, M. and Itô, H. (2002). Capital account liberalization, institutions and financial development: Cross country evidence, NBER Working Paper: Working Paper 8967 . 
Clark, T. and van Wincoop, E. (2001). Borders and business cycles, Journal of International Economics 55: 59-85.

D'Agostino, R. B., Balanger, A. and D'Agostino Jr., R. B. (1990). A suggestion for using powerful and informative tests of normality, American Statistician 44: 316-321.

Danielsson, J. and De Vries, C. (2000). Value at risk and extreme returns, Annales d' Économie et Statistiques 60: 239-270.

De Hoyos, R. and Sarafidis, V. (2006). Testing for cross-sectional dependence in panel-data models, The Stata Journal 6: 482-496.

Dellas, H. and Hess, M. (2005). Financial development and stock returns: A cross country analysis, Journal of International Money and Finance 24: 891-912.

Dungey, M., van Fry, R., González-Hermosillo, B. and Martin, V. (2005). Empirical modeling of contagion: A review of methodologies, Quantitative Finance 5: 9-24.

Engle, R. and Manganelli, S. (2004). Caviar: Conditional autoregressive value at risk by regression quantiles, Journal of Business and Economic Statistics 22(4): 367-381.

Flavin, T., Hurley, M. and Rousseau, F. (2002). Explaining stock market correlation: A gravity model approach, The Manchester School Supplement 2002 pp. 87-106.

Forbes, K. and Rigobon, R. (2002). No contagion, only interdependence: Measuring stock market comovements, The Journal of Finance LVII(5): 2223-2261.

Frankel, J. and Rose, A. (1998). The endogeneity of the optimum currency area criteria, The Economic Journal 108(July 1998): 1009-1025.

Fratzscher, M. (2002). Financial market integration in europe: On the effects of emu on stock markets, International Journal of Finance and Economics 7: 163-193.

Glick, R. and Rose, A. (1999). Contagion and trade: Why are currency crises regional?, Journal of International Money and Finance 18(4): 603-617. 
Goetzmann, W., Li, L. and Rouwenhorst, G. (2005). Long-term global market correlations, Journal of Business 78(1): 1-38.

Hartmann, P., Straetmans, S. and de Vries, C. G. (2004). Asset market linkages in crisis periods, The Review of Economics and Statistics 86(1): 313326.

Heston, S. and Rouwenhorst, K. (1994). Does industrial structure explain the benefits of international diversification?, Journal of Financial Economics 46: 111-157.

Karolyi, A. and Stulz, R. (2003). Are financial assets priced locally or globally, in G.M. Constanides, M. Harris and R. Stulz (eds.), Handbook of the Economics of Finance Edition 1, Vol. 1, Chapter 16: 975-1020.

Koenker, R. and Bassett Jr., G. (1978). Regression quantiles, Econometrica 46: $33-50$.

Krugman, P. (1991). Geography and Trade, MIT Press, Cambridge, MA.

Kuester, K., Mittnik, S. and Paolella, M. (2006). Value-at-risk prediction: A comparison of alternative strategies, Journal of Financial Econometrics 4(1): $53-89$.

Lewis, K. (1999). Trying to explain home bias in equity and consumption, Journal of Economic Literature 37: 571-608.

Longin, F. and Solnik, B. (1995). Is the correlation in international equity returns constant: 1960-1990?, Journal of International Money and Finance 14(1): 3-26.

Miniane, J. (2004). A new set of measures on capital account restrictions, IMF Staff Papers 51(2): 276-308.

Nickell, D. (1981). Biases in dynamic models with fixed effects, Econometrica 49: 1417-1426.

Pesaran, H. (2006). Estimation and inference in large heterogeneous panels with a multifactor error structure, Econometrica 74(4): 967-1012.

Phillips, P. and Sul, D. (2003). Dynamic panel estimation and homogeneity testing under cross section dependence, Econometrics Journal 6: 217-259. 
Phillips, P. and Sul, D. (2007). Bias in dynamic panel estimation with fixed effects, incidental trends and cross section dependence, Journal of Econometrics 137: 162-188.

Quinn, D. (1997). The correlates of change in international financial regulation, American Political Science Review 91(3): 531-551.

Roll, R. (1992). Industrial structure and the comparative behavior of international stock market indices, The Journal of Finance 47(1): 3-41.

Wacziarg, R. and Welch, K.-H. (2008). Trade liberalization and growth: New evidence, The World Bank Economic Review 22(2): 187-231.

Wälti, S. (2006). Stock market synchronization and monetary integration, under review . 


\section{Appendix A: Data Sources}

\section{Stock market indexes}

Thomson Datastream Datastream national stock market indexes. Daily local currency denominated prices from 1974-2006.

\section{Financial liberalization}

IMF Annual Report on Exchange Arrangements and Exchange Restrictions. Capital controls dummy.

Menzie Chinn (KAOPEN). Financial liberalization data on KAOPEN is available from 1974 until 2006. Data for the Netherlands is missing from 1975-1980 and Switzerland 1973-1995. For the Netherlands, assume a gradual linear liberalization between 1975-1980. On the basis of alternative measures (e.g Quinn indicator, IMF Annual Reports on Exchange Rate Arrangements) Switzerland is fully open as of 1974.

\section{Trade integration}

IMF Direction of Trade Statistics. Bilateral import and export data in US\$ from 1974-2006. There is incomplete data for Hong Kong and Singapore (1980-2006) and South Africa. However, most data can be completed by using the trade partner's export and import figures. For Belgium simplifying assumptions are necessary since only data for the Belgium-Luxembourg currency union is available before 1999 .

World Bank World Development Indicators. Nominal GDP in US\$ for all countries 1974-2006.

\section{Industrial structure}

All EU countries, Japan and the United States: EU KLEMS November 2007 (1974-2005). Australia: Australian Bureau of Statistics (1975-2006). Canada: CANSIM (1974-1978) and GGDC 60 Industy database (19792003). Hong Kong and Singapore: GGDC 10-Sector database (1974-2005). South Africa: Statistics South Africa (1986-2006). Switzerland: Statistics Switzerland (1990-2006).

\section{Exchange rate volatility}

Datastream daily exchange rates of all currencies vis-a-vis the UK Pound from 1974-2006. Since 1999 volatility for EMU pairs is zero.

Short term interest rates Global Financial Data, monthly frequency. 


\section{Appendix B: DQ test}

Table 7: DQ test (four lags of "Hit" function))

\begin{tabular}{|c|c|c|c|c|c|c|}
\hline \multicolumn{7}{|c|}{ Local currency denominated returns } \\
\hline & \multicolumn{6}{|c|}{ Quantile } \\
\hline Country & $5 \%$ & $10 \%$ & $25 \%$ & $75 \%$ & $90 \%$ & $95 \%$ \\
\hline Australia & 0.9757 & 0.9308 & 0.0023 & 0.0029 & 0.5347 & 0.2734 \\
\hline Austria & 0.0917 & 0.5312 & 0.2315 & 0.0078 & 0.8529 & 0.3726 \\
\hline Belgium & 0.6336 & 0.4631 & 0.7992 & 0.0586 & 0.4765 & 0.0951 \\
\hline Canada & 0.1134 & 0.5186 & 0.1715 & 0.0091 & 0.0357 & 0.6309 \\
\hline Denmark & 0.9266 & $\mathbf{0}$ & $\mathbf{0}$ & $\mathbf{0}$ & $\mathbf{0}$ & 0.0015 \\
\hline France & 0.2925 & 0.5903 & 0.2738 & $\mathbf{0}$ & 0.2519 & 0.269 \\
\hline Germany & 0.0849 & 0.0732 & 0.0675 & 0.0098 & 0.3837 & 0.4472 \\
\hline Hong Kong & 0.0061 & 0.059 & 0.5163 & 0.0021 & 0.3724 & 0.7125 \\
\hline Ireland & 0.3641 & 0.0848 & 0.1998 & 0.8609 & 0.2677 & 0.526 \\
\hline Italy & 0.7118 & 0.8773 & 0.1259 & 0.3291 & 0.6149 & 0.1132 \\
\hline Japan & 0.984 & 0.0567 & 0.0966 & 0.0015 & 0.8448 & 0.3941 \\
\hline Netherlands & 0.4354 & 0.6084 & 0.305 & 0.0004 & 0.7152 & 0.7204 \\
\hline South Africa & 0.6947 & 0.5677 & 0.0081 & 0.0007 & 0.0057 & 0.1596 \\
\hline Singapore & 0.2135 & 0.5282 & 0.3606 & 0.1924 & 0.045 & 0.4663 \\
\hline Switzerland & 0.7499 & 0.7022 & 0.7066 & 0.0075 & 0.0771 & 0.0645 \\
\hline United Kingdom & 0.7439 & 0.0228 & 0.2974 & 0.0001 & 0.5789 & 0.7518 \\
\hline United States & 0.9896 & 0.8892 & 0.0025 & $\mathbf{0}$ & 0.0482 & 0.8383 \\
\hline
\end{tabular}

Bold numbers indicate rejection of the DQ test at the $1 \%$ critical value. Four lags of the "Hit" function are used. Simone Manganelli's Matlab codes are used to calculate these values. 


\section{Appendix C: Excluded non-trading days}

Table 8: Non-trading days (excluded from analysis)

\begin{tabular}{ll|ll}
\hline \hline Year & Dates & Years & Dates \\
\hline 1974 & $1 / 1,12 / 4,15 / 4,27 / 5,26 / 8,25 / 12,26 / 12$ & 1991 & $1 / 1,29 / 3,1 / 4,25 / 12,26 / 12$ \\
1975 & $1 / 1,28 / 3,31 / 3,26 / 5,25 / 8,25 / 12,26 / 12$ & 1992 & $1 / 1,17 / 4,20 / 4,25 / 12$ \\
1976 & $1 / 1,16 / 4,19 / 4,30 / 8$ & 1993 & $1 / 1,9 / 4,12 / 4,31 / 5$ \\
1977 & $8 / 4,11 / 4,7 / 6,26 / 12$ & 1994 & $1 / 4,4 / 4,26 / 12$ \\
1978 & $27 / 3,1 / 5,25 / 12,26 / 12$ & 1995 & $14 / 4,17 / 4,25 / 12,26 / 12$ \\
1979 & $1 / 1,13 / 4,16 / 4,25 / 12,26 / 12$ & 1996 & $1 / 1,5 / 4,8 / 4,27 / 5,25 / 12,26 / 12$ \\
1980 & $1 / 1,4 / 4,7 / 4,26 / 5,25 / 12,26 / 12$ & 1997 & $1 / 1,28 / 3,31 / 3,25 / 12,26 / 12$ \\
1981 & $1 / 1,17 / 4,20 / 4,25 / 12$ & 1998 & $1 / 1,10 / 4,13 / 4,24 / 12,25 / 12$ \\
1982 & $1 / 1,9 / 4,12 / 4,3 / 5,31 / 5$ & 1999 & $1 / 1,2 / 4,4 / 4,31 / 12$ \\
1983 & $1 / 4,4 / 4,26 / 12$ & 2000 & $21 / 4,24 / 4,1 / 5,25 / 12$ \\
1984 & $20 / 4,23 / 4,25 / 12,26 / 12$ & 2001 & $1 / 1,13 / 4,16 / 4,25 / 12,26 / 12$ \\
1985 & $1 / 1,5 / 4,8 / 4,27 / 5,25 / 12,26 / 12$ & 2002 & $1 / 1,29 / 3,1 / 4,25 / 12,26 / 12$ \\
1986 & $1 / 1,28 / 3,31 / 3,25 / 12,26 / 12$ & 2003 & $1 / 1,18 / 4,21 / 4,25 / 12,26 / 12$ \\
1987 & $1 / 1,17 / 4,20 / 4,25 / 12$ & 2004 & $1 / 1,9 / 4,12 / 4$ \\
1988 & $1 / 1,1 / 4,4 / 4,26 / 12$ & 2005 & $25 / 3,28 / 3,26 / 12$ \\
1989 & $24 / 3,27 / 3,25 / 12,26 / 12$ & 2006 & $14 / 4,17 / 4,1 / 5,25 / 12,26 / 12$ \\
1990 & $1 / 1,13 / 4,16 / 4,25 / 12,26 / 12$ & & \\
\hline
\end{tabular}

